\title{
Research on Contemporary Ideological and Political Education Mode Based on Modern History
}

\author{
Chen Wang ${ }^{1}$, Pingjing Chang ${ }^{2}$ \\ ${ }^{1}$ Wuhan Business University, Department of Ideological and Political Theory, Hubei, Wuhan, 430056 \\ ${ }^{2}$ History College of Wuhan University, Hubei, Wuhan, 430072
}

Keywords: Contemporary Ideological and Political Education Mode, Modern History

\begin{abstract}
The model of ideological and political education is a link and intermediary that penetrates the theoretical form and practice of ideological and political education. Since the establishment of the discipline of ideological and political education, some progress has been made in the practice and research of ideological and political education. Through the systematic review of the research on the ideological and political education mode by modern history, this article analyzes the achievements and shortcomings in it, which helps us to further explore the formation mechanism and growth potential of the modern ideological and political education mode.
\end{abstract}

\section{Introduction}

The so-called model is the things or activities by a number of inter-related elements, with a typical model of a simplified model or paradigm. In essence, the ideological and political education mode is a link and intermediary that penetrates the theoretical form and practice of ideological and political education. In the past researches on ideological and political education, there existed the contradiction and separation between theory and practice. The root of the researches in ideological and political education lies in a non-one or two-dimensional way of thinking - either based on theory or based on practice rather than relational way of thinking. The thinking mode of this kind of research makes the theory of ideological and political education cannot effectively guide the practice and solve the problems encountered in reality, thus resulting in the poor practical effectiveness of the ideological and political education. Some scholars point out that the study of educational mode precisely makes itself an independent form of educational knowledge based on the dual relevance between theory and practice, and realizes the transition from educational theory to educational practice, resulting in strong practical explanatory power and reforming power can be seen in the study of ideological and political education, ideological and political education model occupies an important position [1]. Although the progress and achievements of the research on the ideological and political education model have not been quite remarkable in the past 30 years, the analysis of the concept and the preliminary development of related researches have promoted the deepening of the entire profession of ideological and political education and its research effect.

\section{Explore Chinese Traditional Ideological and Political Education Mode}

From the perspective of the modernization of disciplines, it is not enough for a country to develop modernized education that is in line with its own characteristics and promote the discipline education in its own country. It is not enough just to follow the path of exogenous resources and learn from the modern educational resources and experience of other countries. The traditional model of ideological and political education can provide useful reference to the methods and ways of constructing the contemporary model of ideological and political education, as well as its rational inheritance and rational acquisition of the content in principle, in order to realize the contemporary ideological and political education mode development provides endogenous support [2].

The traditional model of ideological and political education in our country includes both the ideological and political education model of Confucianism in ancient times and the ideological and 
political education model of our party in the revolutionary period. Chinese traditional ideological and political education has two aspects: ancient tradition and revolutionary tradition. The ancient Chinese model of ideological and moral education is based on ancient ethics. Guided by such an ethical and moral system, an educational model with ancient Chinese characteristics has been formed. The ideological and political education model with the revolutionary tradition is a model with broad mass and obvious authority. This model has adapted to the situation that Marxism has a broad mass base and authority, and the party organizations and leaders have lofty prestige. They played a great role in the past times.

\subsection{Ideological and political education mode of ancient society}

The model of ideological and political education in ancient Chinese society is based on the political ethics of the same family and nation. Under the goal of ideological and political education based on the ideal personality of the gentleman and the saint, a set of relatively complete educational model has been established. From 2007 to 2008, Tang Guowun conducted a systematic study of the traditional Confucian ideological and political education model. He pointed out that Confucianism is the main direct designer of Chinese traditional political culture and its core is to instill the political ideals of the public through the traditional ideological and political education and enlighten the political psychology, political feelings and political values it expects. To emphasize that Chinese moral education faces three major issues: globalization, modernization, and realization. Nationalization is an important aspect of moral modernization. Chinese modernization of morality must find the root cause and the source of living water in its moral tradition and carry out this Creative transformation in order to establish the value structure and operational principle of Chinese moral education, which is possible to create a Chinese-style model of moral education. Based on the study of traditional Confucianism, Huang Shuguang put forward that Confucianism is the mainstream of traditional Chinese society Based on the theory of human nature, the moral nature is the common feature of the Confucian enlightenment thought in different historical periods. It analyzes the unique ethical and political demands of Confucian enlightenment and its strict system of organization and operation. For contemporary moral education and spiritual civilization construction no inspiration Huang Shuguang Wang Lei and China are respectively the traditional education model deconstruction and the transformation of modern China made a thorough analysis of the reasons parsing and social background [3].

\subsection{The ideological and political education during the revolutionary mode}

At present, there are seldom specialized researches on the ideological and political education model in the revolutionary period. Most of the existing researches are contained in the introduction of the historical evolution of the ideological and political education since the founding of the Chinese Communist Party. Among them, Xu Qixian and Liu Jianjun The history of the ideological and political education of the Communist Party of China, the history of the ideological and political education of the Communist Party of China edited by Wang Shuming. These works systematically elaborate the development of the Chinese Communist Party's ideological and political education, introduce and analyze the different modes of ideological and political education conducted by the Communist Party of China in different historical periods, summarize the historical experience and lessons of the CPC's ideological and political education, With the development of the ideological and political education in the Communist Party of China, combined with the actual interpretation of some important principles of ideological and political education, we can provide some empirical reference and historical reference for the discussion and resolution of the current ideological and political education.

\section{The Construction and Study of Contemporary Ideological and Political Education in Our Country}

On the basis of introducing and drawing lessons from foreign models of ideological and political education actively, the pattern of ideological and political education in our country started the 
theoretical exploration of the construction of ideological and political education patterns. In western countries, the theory of ideological and political education (generally referred to as moral education) precedes the pattern of ideological and political education. The construction of the model of ideological and political education has its own theory as the basis and basis. However, as a discipline, ideological and political education in China was not formed until the mid-1980s. Its theoretical and practical model is constantly enriched and developed in the interweaving process. The enrichment of the ideological and political education theory provides a theoretical basis and academic resources for the construction of the ideological and political education mode. The establishment of the ideological and political education mode further ameliorates the deficiency of theoretical development and generates new values of ideological and political education.

After many years of practical exploration and theoretical refinement, our country's ideological and political education has formed its own unique following several basic modes.

\subsection{The subjective mode and intersubjective mode}

The traditional model of ideological and political education mainly adopts the objectivity model of inculcating law. Instilling law is the dominant mode of ideological and political education in China. However, due to the education method emphasizes the subjectivity of educators and ignores the subjectivity of educators and the moral education is easy to be disconnected with the development of human beings. As a result, there is still a gap between the achievements made in ideological and political education and the goals set. To make up for this gap, we must not rigidly adhere to the conventions of "inculcating the Education Law," but pay special attention to the diversification of the ideological education model and the diversification of its implementation. As a special form of education, ideological and political education follows the existing paradigm of education in its practical process and changes with the change of educational paradigm. That is, ideological and political education itself has experienced the model of the theoretical foundation of education based on the theory of object of education and education. With the proposition of "intersubjectivity" in philosophy and its application in education, it has made up and perfected the defects of the subjectivity itself, that is, the one-dimensional analysis. Therefore, ideological and political education should resort to dialogue, Communicative practice and other ways to construct the intersubjectivity model.

The subjectivity model is based on the moral development needs of educators. Educators and educators are in an equal interactive position, respecting the right to self-development of educators, giving full play to educators and education in ideological and political education So as to achieve the common requirement of cultivating and bringing up the subjectivity of the educated. This model places educators and educators on an equal footing and advocates that in the process of education, the subject and object passing through the "Acceptance" can be transformed into each other and the virtuous interaction between teaching and learning can be realized [4]. As can be seen, the mode of subjective education for the establishment of individual subject, the positive influence of rational release is unmatched by the traditional objective education mode, but the subjectivity mode also lurks inherent crisis, which is that it unconsciously shapes the human treatment of nature Anthropocentrism, and individualistic individualism toward others, "have led to the insolence and proliferation of individual subjectivity. To solve this crisis, the subjectivity model of ideological and political education will inevitably need to move toward the inter-subjectivity model.

\subsection{Cognitive-oriented model, emotional-oriented model and behavior-oriented model}

Cognitive-oriented model is a model of moral education based on cultivating the moral cognition ability of educated people (including the rational ability of moral judgment, reasoning, choice and reflection) and emphasizes the value of moral knowledge and moral cognitive ability and use as the basic characteristics. Chinese ideological and political education has always attached great importance to the education of ideological, political and moral aspects of education, emphasizing the value and application of moral knowledge and moral cognition, opposing moral norms and values, advocating moral dilemmas Law, Clarification of Value, Reflecting Law, and so on, to guide the educated people to think rationally about moral issues, and advocate that moral education 
should focus on the cultivation of moral rationality and the self-construction of individuals as moral subjects. The problem with this model is that it places rational self-determination at the center of morality, creating an overemphasis on the cultivation of moral cognitive abilities in practice that overlooks the shaping of other abilities, leading to the lack of moral force and estrangement of good life Problem is to cultivate a moral literate who has a high literacy in his intellectual thinking but who is morally dissatisfied with moral ethics and cannot prove correct logical reasoning and high-level thinking ability and rationality both theoretically and in practice There is a certain necessary relationship between the behavior. "

\subsection{Network ideological and political education model}

Luo Jiaying put forward the theoretical assumption that the construction of moral education mode under the influence of internet should be based on the network construction of moral education mode in order to achieve the goal and goal of moral education in colleges and universities [5]. Network under the influence of moral education in colleges and universities should take "student-oriented", closely around the moral aesthetic and activities. Its mode of construction, one should be based on human education and human-based theory as the theoretical basis, the establishment of "student-oriented" The logical starting point and value orientation; the second is based on the ethical aesthetic "of the inherent provisions of the organization of moral education activities and processes in colleges and universities. The rationality of building a humanized aesthetic mode is confirmed from three aspects: the rationality of moral education in colleges and universities, the rationality of constructing methodology of models, the content selection and the rationality of process organization [6].

Web3.0's intelligent information retrieval and analysis provides a favorable tool for comprehensively weighing, comparing, judging and evaluating people's ideological and political education status. Some scholars started from the environmental changes to analyze the impact of internet on moral education in colleges and universities and the countermeasures to build a new pattern of moral education in colleges and universities. It proposed to take the initiative to occupy the commanding height of the network and establish an interactive platform for teachers and students to exchange ideas on equal footing; to strengthen campus network management, Network culture of the main front, with a view to making the current moral education in colleges and universities to adapt to the needs of the Internet age, and promote the all-round development of college students.

\section{Conclusion}

Today, with the globalization of the Internet, by studying the characteristics and laws of the modern history, we can learn from the advanced experience of the developed countries in ideological and political education. We should constantly adjust the educational content and methods of education in our ideological and political education, update our educational concepts and innovate the educational model so as to adapt to the development of the times so as to enhance and improve the effectiveness of our ideological and political education.

\section{References}

[1] Yu Chengxue, Wang Zhongqiao. Discussion on the work pattern of ideological and political education of communicative college students[J]. Research in Ideology, 2008 (09). $42-45$

[2] Zhang Meijuan. Emotional effects: a new horizon out of the plight of ideological and political education[J]. Ideological and Educational Research. 2007 (07). 48-58

[3] Cheng Yuan. On Emotional Experience in Emotional Education[J]. Exploration of Education. 2007 (05).112-115

[4] Jia Yanchun. Emotional Education Act in Political Science Teaching[J]. Vocational Education Research. 2007 (03).87-89 
[5] Wang Qiuying. Emotional education - a new thinking of ideological and political education in colleges and universities[J]. Journal of Shenyang Institute of Education. 2007 (01).125-127

[6] Lu Jiamei. On the emotional teaching model[J]. Educational Research. 2006 (12).88 